\title{
Drug Treatment Value in a Changing Oncology Landscape: A Literature and Provider Perspective
}

\author{
Christian Frois, PhD; Andrew Howe, PharmD; John Jarvis, MBA; Kathryn Grice, BA; \\ Ken Wong, PharmD; Christopher Zacker, PhD; and Rahul Sasane, PhD
}

\begin{abstract}
BACKGROUND: The U.S. health care system's transition to a value-based reimbursement model holds important implications for medical innovation, care delivery, and value-based assessments of therapeutic interventions. This transition has been especially noteworthy in oncology, with substantial ongoing changes to payer reimbursement and the provider landscape, as well as the introduction of value frameworks to guide drug treatment decision making. The implications of these changes for provider assessments of drug value and evidence needs remain unclear.
\end{abstract}

OBJECTIVES: To understand provider perspectives on drug value assessment and the utility of existing oncology value frameworks by identifying (a) key value-based trends in the evolving oncology landscape, (b) provider definitions of drug value, (c) the role of existing value frameworks in provider decision making, and (d) future provider evidence needs for making value-based treatment decisions.

METHODS: We conducted a literature review to identify existing oncology value frameworks and definitions of drug treatment value in oncology. Using a structured discussion guide informed by this literature review, we conducted 12 telephone-based in-depth interviews in November and December 2017 with U.S. oncology providers involved in organizational drug treatment and formulary decision making within their practices. Responses to interview questions were analyzed and reported as averages and percentages across participants.

RESULTS: Of 293 publications identified by keyword searches, 35 relevant articles were identified. Among these, the literature review identified no common definition for providers to assess drug value. Interview research participants described large ongoing changes in the oncology provider landscape, with economic pressures from payers as the foremost leading factor. Although 5 value frameworks were found in the literature, interviews found that in practice few providers consider these value frameworks to be key influences when evaluating treatment or formulary decisions. Furthermore, while $83 \%$ of participants' organizations employed some form of internal clinical pathways, only the minority $(25 \%)$ with pathways integrated in their electronic medical record (EMR) systems saw these pathways as significantly affecting clinicians' drug treatment decision making. To aid the ongoing shift from volume-based to value-based care, we found that, rather than value frameworks, providers are looking for patient-level tools to make more appropriate drug decisions.

CONCLUSIONS: Payer reimbursement pressures are leading to radical changes in the oncology provider landscape, and there is a need for improved guidance for providers in assessing drug value. In particular, this study identifies the need for a timely and multifaceted summary of information required to assess the value of alternative treatment options for a given patient. Manufacturers also need to make significant strides to help generate and improve the dissemination of evidence to support the value of their therapies.

J Manag Care Spec Pharm. 2019;25(2):246-59

Copyright $\odot 2019$, Academy of Managed Care Pharmacy. All rights reserved.

\section{What is already known about this subject}

The oncology landscape is undergoing significant changes in response to increasing payer pressures and new reimbursement challenges.

Although historically insulated from payer pressures, providers are becoming increasingly forced to incorporate value-based considerations in oncology drug treatment decisions.

New value frameworks are emerging to guide value-based treatment decisions as the U.S. health care system moves away from fee-for-service and toward value-based reimbursements.

\section{What this study adds}

There is a lack of clear definition of drug value in oncology in the reviewed literature and our sample of U.S. providers.

Existing value frameworks play a limited role in guiding oncology drug selection at population and individual levels.

There is a need for an oncology value platform, that is, a tool to provide, for a given cancer patient, a comprehensive and timely summary of available data informing value to guide providers' drug treatment decision making.

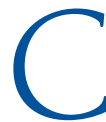
ancer is a leading cause of death and increasingly prevalent in the United States, placing substantial demand on the health care industry's clinical resources. ${ }^{1,2}$ As the fifth largest source of medical expenditures for U.S. patients, ${ }^{3}$ oncology is an area of particular concern to U.S. payers and society.

Attempts to mitigate rising oncology costs have led to a shift from volume-based to value-based care, resulting in the introduction of alternative payment models, innovative provider contracting, and new value frameworks.,4-8 This transition to value-based care is changing established delivery models, treatment decision making, and drug reimbursement in oncology, bringing considerations of treatment value to providers' treatment and formulary decision making. One recent study among 202 oncologists reported that more than half of surveyed providers believed the control of overall cancer care costs (63\%) and specialty drug costs (57\%) to be among the most pressing challenges in oncology. ${ }^{9}$ 
Historically, drug prices and reimbursement were not a significant concern for oncology providers under the traditional fee-for-service buy-and-bill system. ${ }^{10}$ Drugs were a key source of revenue for oncology providers before the implementation of the 2006 Medicare Modernization Act and associated cap on Medicare reimbursement at $6 \%$ of average sales price. ${ }^{10-12}$ With the Budget Control Act of 2011, this reimbursement cap was reduced to $4.3 \%$, and commercial insurers followed suit, further influencing oncology providers' practice economics. ${ }^{10,11,13}$ Additionally, payers have demonstrated increasing willingness to refuse or restrict reimbursement for some therapeutic regimens based on lack of evidential support or drug manufacturer contracts. ${ }^{14,15}$ These payer-related pressures have increased financial risks, accelerated existing trends of consolidation, and added financial strain to oncology practices throughout the United States. ${ }^{16}$

As oncology practices are increasingly forced to weigh treatment costs and reimbursement against clinical benefits, provider organizations have begun adopting internal utilization management measures, including clinical pathways and formularies to better align care provision with value. ${ }^{6,7,10,17}$ In response to this heightened focus on treatment value, multiple organizations such as the American Society of Clinical Oncology (ASCO), National Comprehensive Cancer Network (NCCN), and Memorial Sloan Kettering Cancer Center (MSKCC) have developed frameworks designed to assist stakeholders in the systematic assessment of drug value in oncology. ${ }^{18-20}$ These value frameworks attempt to reconcile clinical, economic, and social factors in defining value, either by generating a qualitative output that allows for comparison of overall rankings between drugs or a quantitative output that allows for comparison between drug prices and estimated value., ${ }^{4}$,

Although research has explored the potential benefits of new value frameworks and payment models for oncology stakeholders, ${ }^{4,6,17,22,23}$ gaps exist in understanding how changes to the oncology landscape are affecting provider drug value assessments, how physicians are currently utilizing value frameworks in their treatment decisions, and the implications for new provider evidence needs. Given providers' central role in ensuring that value is maximized for all stakeholders in health care, further understanding of how providers define and assess product value is needed. In this article, we report findings from a literature review, as well as primary research results from interviews with formulary decision makers at 12 oncology practices. In both, the following were assessed: (a) key value-based trends in the evolving oncology landscape, (b) provider definitions of drug value, (c) the role of existing value frameworks in their decision making, and (d) providers' future evidence needs for making value-based treatment decisions.

\section{Methods}

Our research consisted of a literature review of key articles on drug treatment value in oncology and primary in-depth interviews conducted among U.S. oncology providers.

\section{Literature Review}

A literature review was conducted to identify relevant articles and capture key information on existing value frameworks and care delivery models in oncology. This review aimed to identify current and anticipated value-based trends in oncology, as well as the design of primary provider research. The literature search used select keywords, covering full-text articles in the Embase, MEDLINE, and PubMed databases to identify articles focused on value, value frameworks, and alternative payment models in oncology (Appendix A, available in online article). The search was limited to English-language articles, and duplicate citations from overlapping database coverage were excluded. Two independent reviewers screened titles and abstracts to identify policy-oriented studies focused on valuebased care and related to drug treatment in oncology. Selected papers were reviewed to identify definitions of drug value, as well as existing value frameworks in oncology and how they may affect future oncology payment and care models. For all identified value frameworks, key publications defining and summarizing these value frameworks were included in the literature review. The literature review was conducted in accordance with PRISMA guidance. ${ }^{24}$

\section{Oncology Provider Interview Research}

Twelve 1-hour interviews with U.S. oncology providers captured perspectives across different treatment settings. A structured questionnaire was developed to guide the interviews using information obtained from the literature review. Interview questions focused on key issues and changes in the oncology landscape, the process and definitions for assessing drug value at provider organizations, and provider evidence needs implications.

Physician recruitment was conducted between November and December 2017 via e-mail using a proprietary physician list. Potential participants were screened to ensure oncology specialization and involvement in oncology drug decision making at their institutions. Additional screening considerations included providers' practice size (e.g., participants from solo private practices were excluded from this research) and selfreported knowledge of alternative oncology payment models, clinical pathways, quality, and/or value assessment approaches in oncology.

Interviews were conducted via telephone, with videoconference software and online exhibits to facilitate discussion. Each value framework was discussed individually with participants, and participants were presented information on the characteristics, value definitions, and target audiences for value frameworks 


\begin{tabular}{|c|c|}
\hline \multicolumn{2}{|c|}{$\begin{array}{l}\text { Detailed Characteristics of Interviewed } \\
\text { Providers }\end{array}$} \\
\hline Characteristics & Number of Providers $(\mathrm{N}=12)$ \\
\hline $\begin{array}{l}\text { Participant organization types } \\
\text { (primary practice) }\end{array}$ & $\begin{array}{l}\text { - Private clinics: } 4 \\
\text { - Academic hospitals: } 4 \\
\text { - Nonacademic hospitals: } 4\end{array}$ \\
\hline Participant roles & $\begin{array}{l}\text { - Medical directors/officers: } 11 \\
\text { - Pharmacy-related administrator: } 1\end{array}$ \\
\hline Participant primary specialty & $\begin{array}{l}\text { - Hematology-oncology: 9; } \\
\text { oncology: } 3\end{array}$ \\
\hline $\begin{array}{l}\text { Participant number of years in } \\
\text { current role }\end{array}$ & $\begin{array}{l}-<10 \text { years: } 4 \\
\text { - } 10-20 \text { years: } 8\end{array}$ \\
\hline $\begin{array}{l}\text { Number of cancer patients treated } \\
\text { by organization per year }\end{array}$ & $\begin{array}{l}\cdot \leq 15,000 \text { cancer patients: } 7 \\
\text { - > 15,000 cancer patients: } 5\end{array}$ \\
\hline $\begin{array}{l}\text { Average familiarity with value } \\
\text { frameworks in oncology }{ }^{a}\end{array}$ & $\begin{array}{l}\text { - NCCN Evidence Blocks: } 6.6 \\
\text { - ASCO value framework: } 5.3 \\
\text { - MSKCC DrugAbacus: } 3.7 \\
\text { - ICER value framework: } 2.1 \\
\text { - ESMO Magnitude of Clinical } \\
\text { Benefit Scale: } 0.6 \\
\end{array}$ \\
\hline $\begin{array}{l}{ }^{a} 0=\text { not familiar; } 10=\text { very familiar } \\
\text { ASCO =American Society of Clinical O } \\
\text { for Medical Oncology; ICER = Institute } \\
\text { MSKCC= Memorial Sloan Kettering Co } \\
\text { Comprehensive Cancer Network. }\end{array}$ & $\begin{array}{l}\text { gy; ESMO = European Society } \\
\text { linical and Economic Review; } \\
\text { Center; NCCN = National }\end{array}$ \\
\hline
\end{tabular}

with which they had low self-assessed familiarity (defined as a 4 or lower on a 0-to-10 scale). Participants were anonymized and blinded to the study sponsor, and no identifying information about the providers was shared. All study data were collected and analyzed by the subset of authors unaffiliated with the study sponsor to avoid conflicts of interest and preserve participant anonymity. Honoraria were provided to participants as compensation for their time. Averages, percentages, and counts were reported for questions that asked participants to provide rankings. No institutional review board approval was sought, as this research did not involve patients and was conducted in a voluntary and informed manner by participants.

\section{Results}

\section{Literature Review}

After the suppression of duplicates, our initial electronic database search resulted in the identification of 293 unique articles. After title and abstract screening for relevance to drug treatment value and value frameworks in oncology, 35 articles were included in the literature review for the current study.

Definitions of Drug Value in Oncology. Though multiple methods for considering drug value in oncology were documented across the literature reviewed, no commonly agreedupon definition was identified for determining drug value. ${ }^{25-28}$ Reported methods included a mix of quantitative (e.g., ratio of outcome to cost) and qualitative (e.g., perceived health benefit) approaches; however, none were commonly recognized nor designed from a multistakeholder perspective. ${ }^{27}$ Although a universal definition of drug value in oncology was not identified in the literature, study findings indicate that clinical efficacy remains the primary factor in providers' perception of treatment value; 1 study of 231 oncology providers reported that $74 \%$ viewed clinical efficacy as the most important factor shaping perceived value of a new cancer drug, with fewer reporting cost-effectiveness (11\%), impact on quality of life (9\%), or safety and tolerability (6\%) as the dominant factor. ${ }^{26}$

Oncology Value Frameworks and Their Characteristics, Five key oncology value frameworks were identified in the literature review: ASCO's Value Framework, ${ }^{18,29}$ NCCN's Evidence Blocks, ${ }^{19}$ MSKCC's DrugAbacus, ${ }^{20}$ the Institute for Clinical and Economic Review's (ICER) Value Framework, ${ }^{30}$ and the European Society for Medical Oncology's (ESMO) Magnitude of Clinical Benefit Scale. ${ }^{31}$ The ASCO, ESMO, and NCCN value frameworks provide qualitative measures of drug value, and the MSKCC and ICER value frameworks provide a single "break even" price point to assess a product's "net value." Although all 5 value frameworks have been developed to guide stakeholder drug value decisions, the NCCN and ASCO value frameworks are intended for use among providers and patients to support shared decision making for patient-level treatment, and the ICER, MSKCC, and ESMO value frameworks are intended for use by payers and policymakers to inform population-level drug value assessments (Appendix B, available in online article).

Beyond a common focus on overall survival (OS) and safety, discrepancies exist in these frameworks' considerations of cost and evidence. Studies indicated a large variability and lack of transparency across the different value frameworks, with differences in methodology leading to significant variation in output and difficulties in comparing measures of value, ${ }^{25,32-34}$ particularly for new therapies. ${ }^{21,35}$ According to 1 survey-based study, $47 \%$ of payers do not expect that value frameworks will influence value assessment of oncology drugs in the future. ${ }^{21}$ Some studies cite the lack of patient-specific inputs in existing value frameworks as a potential barrier to uptake among oncology providers., ${ }^{41,27,36}$ We found no mention in the reviewed literature of any U.S. value-based arrangements for oncology therapies that use value frameworks.

\section{Provider Interview Research}

Interview Participant Characteristics. All 12 participants were closely involved in oncology drug treatment and formulary decision making within their organizations. The participant sample was from a variety of oncology treatment settings, reporting their primary practice as private clinic (33\%), academic hospital (33\%), or nonacademic hospital (33\%). Eleven 


\section{FIGURE 1 Current and Future Provider Use of Value Frameworks}

"Is your practice currently using any of these oncology value frameworks?

Do you see value frameworks playing a greater role in career patient care decisions?"

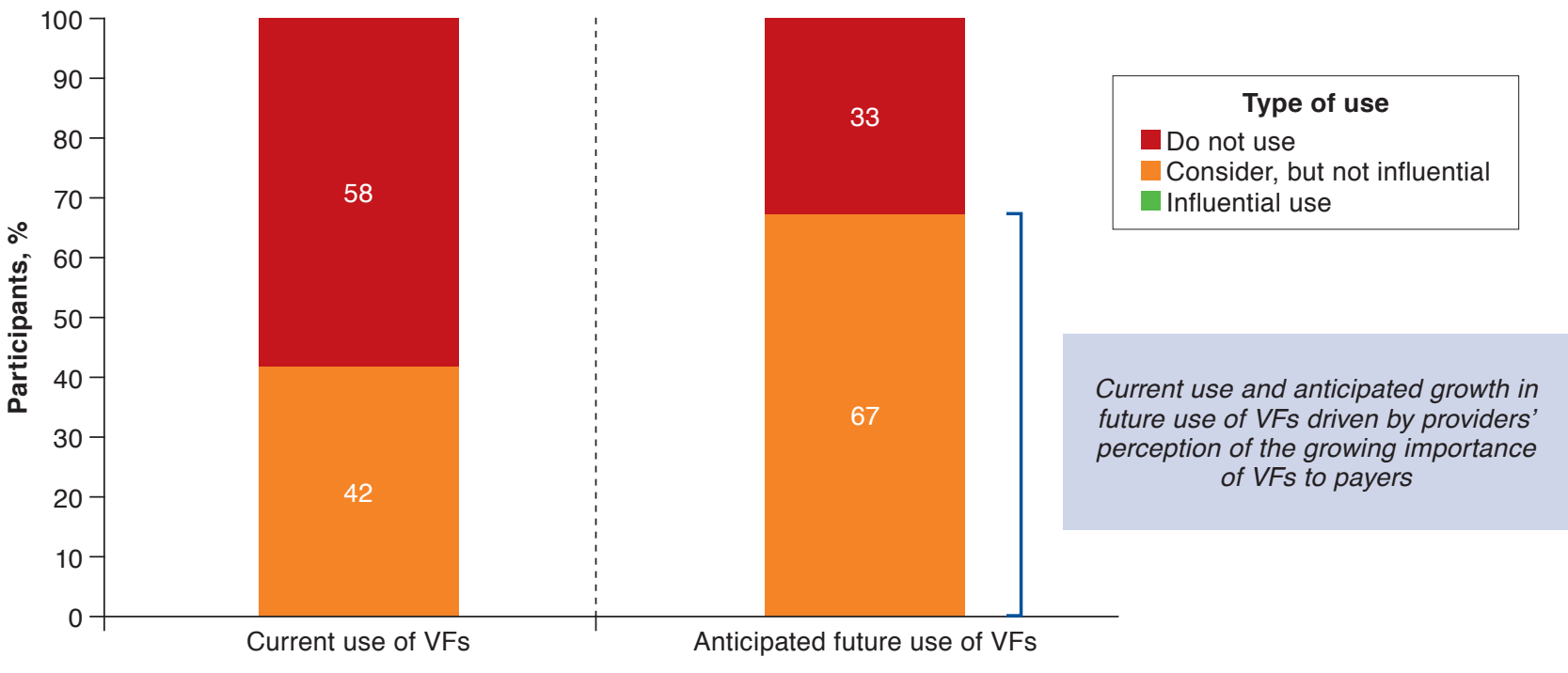

VF= value framework.

had medical director/officer roles at their organizations, and 1 had a pharmacy-related administrative role (i.e., clinical pharmacist). Most participants (66\%) had occupied their current role for at least 10 years. Provider organizations included a mix of small and large oncology-treatment practices/centers. Detailed characteristics of the interviewed participants are presented in Table 1.

Oncology Provider Drug Decision Making and Consideration of Value. Interviewed physicians described a rapidly evolving oncology landscape with large changes to payer reimbursement and contracting, rising launch prices for new drugs, increased provider consolidation, improved patient survival, new treatment options (e.g., immunotherapies and biosimilars), health care reform uncertainty, and the introduction of value frameworks to aid value-based decision making. Interviewed providers described the process for assessing drug value within their organizations as primarily driven by the lack of a clear drug value definition, payer pressures, provider perception of value, and practice restrictions.

Lack of a clear drug value definition. While all interviewed providers were familiar with at least 1 value framework (Table 1), providers were most familiar with the NCCN and ASCO value frameworks. We found that few providers considered value frameworks to be key factors when evaluating treatment or formulary decisions and did not expect this to change without payer action (Figure 1). Furthermore, this finding did not appear to be dependent on providers' familiarity with value frameworks, as even participants with greater value-framework familiarity shared this perspective. To address information gaps for alternative therapies, 3 providers discussed sometimes referring to the NCCN Evidence Blocks (25\%) and 2 to the ASCO Value Framework (17\%) when making treatment decisions. While these providers considered value frameworks to be additional sources of information when making treatment decisions, they did not consider value frameworks to be influential in their decision making or substitutes for clinical efficacy considerations.

The limited focus on value frameworks appears to reflect a lack of a clear drug value definition within and across oncology practices. Among all interviewed providers, none belonged to an organization with an explicit definition of drug value that guides drug treatment or assessments. Instead, drug value assessments appear to be made through consensus-based alignment between internal clinical stakeholders with NCCN guidelines and available clinical trial data as key inputs. While all providers anticipated value frameworks to become more prominent in the future due to continued economic pressures from payers, half of all interviewed providers suggested that formal reliance on value frameworks when making treatment decisions will not occur until clearer, common guidance is provided from oncology stakeholders (e.g., payers, NCCN, patient advocacy groups) and frameworks are explicitly integrated within payer reimbursement models. 
"On a scale of 0 to 10 , how would you rate the importance of the following changes for your organization and the delivery of care to cancer patients?"

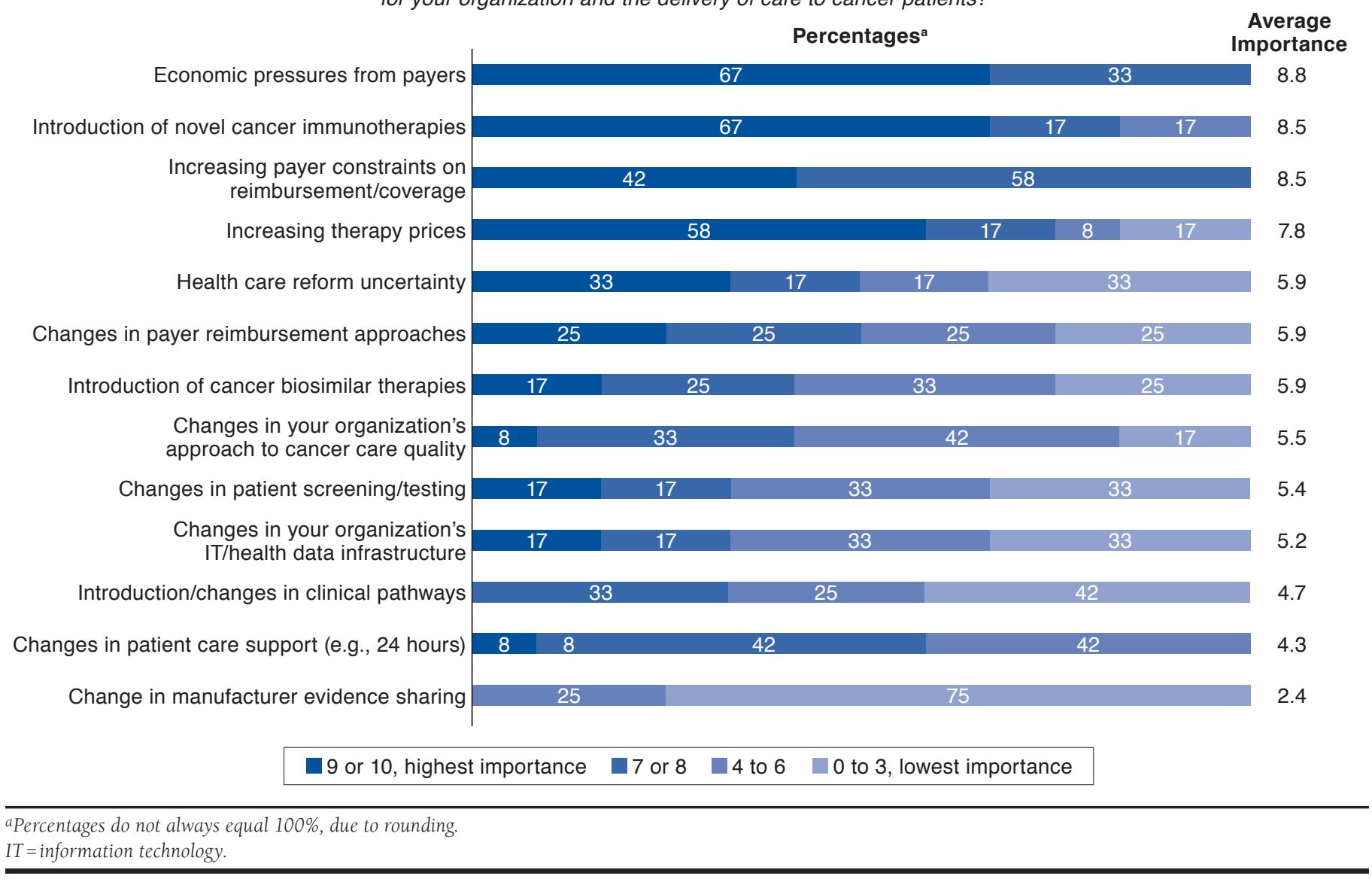

Payer pressures. Economic pressures from payers, particularly related to reimbursement risk for drug therapies, were seen as the most important consideration currently impacting the oncology landscape. When prompted to rate the importance of value-related factors affecting their organization and the delivery of patient care, $67 \%$ of interviewed providers considered economic pressures from payers of highest importance (Figure 2). This was on par with the introduction of novel cancer immunotherapies (67\%), increasing therapy prices (58\%), and increasing payer constraints on reimbursement/ coverage (42\%). Feedback from providers suggests that payer pressures and nonreimbursement risk are becoming increasingly formalized through payer pathways among national and dominant regional insurers. Providers described the growing administrative and logistical burden required to advocate for payer reimbursement in instances where treatment decisions are not aligned with payer pathways.
Provider perception of value. Interviewed providers consistently reported medical value and improved clinical efficacy (e.g., gains in OS, reduced toxicity) as the most important factors driving physicians' perceptions of treatment value (Figure 3). In particular, cost/economic, system/organization, and societal values were seen as playing a limited role in influencing drug value assessments. Providers' perceptions of drug treatment value were also influenced by patient populations at their practices; while providers at large hospitals and academic centers generally preferred to treat patients with novel/cutting-edge therapies, providers at smaller community practices typically sought to balance treatment efficacy with adequate/improved tolerability, convenience, and quality of life. Nearly all participants (83\%) indicated that patients' ability to afford treatment copayments was a key influence on their perception of drug value, both as a potential treatment barrier for patients and a source of increased financial risk for their practices. This feedback suggests that providers' perception of drug value is driven 
“To what extent do the following factors influence your assessment of drug treatment value?"

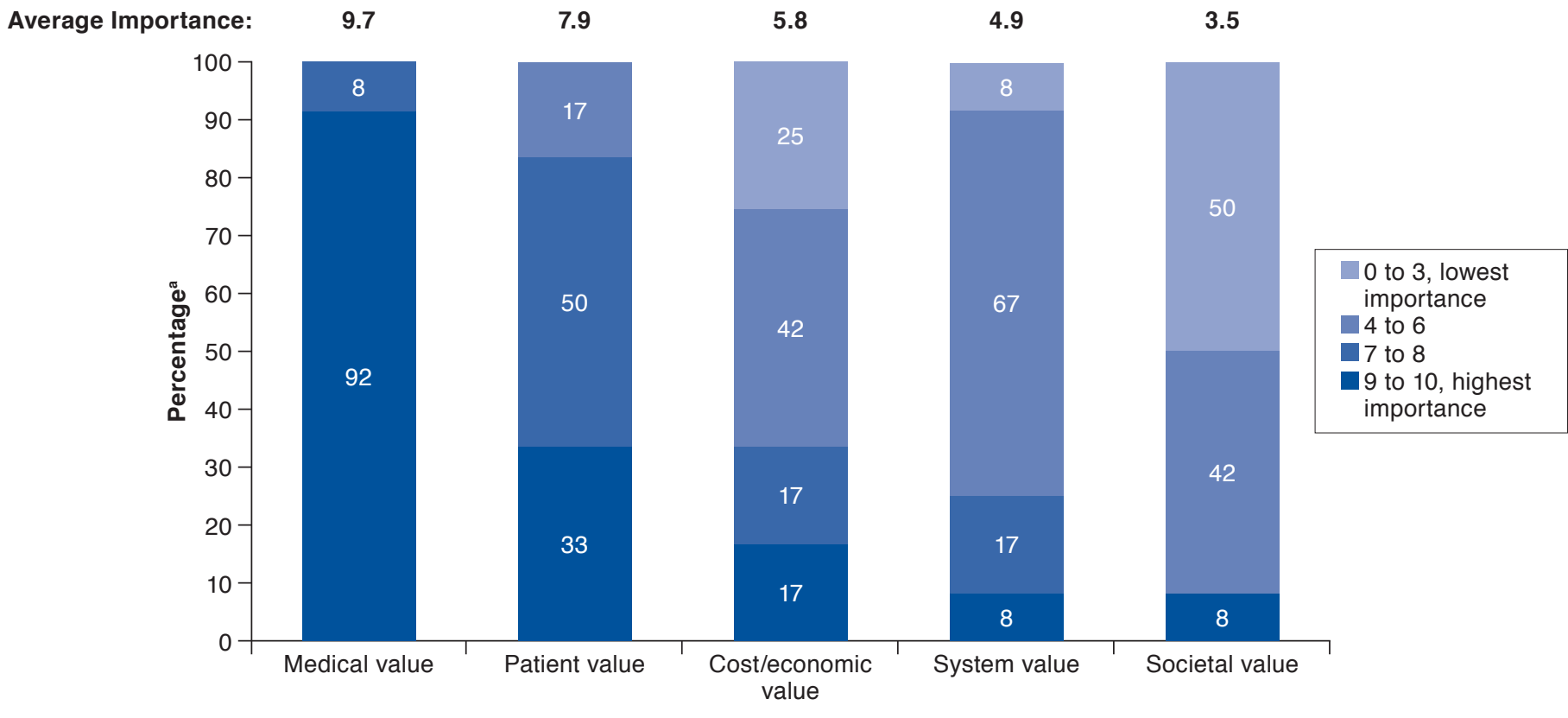

apercentages do not always equal $100 \%$, due to rounding.

in large part by demands from individual patients, customers whose needs must be satisfied to ensure financial sustainability for their practices.

Practice restrictions. Providers described formal drug value assessments within their organizations as a consensus-based process among members of their organizations' P\&T (pharmacy and therapeutics) committees. Similar to provider perceptions of drug value, P\&T committee discussions, and decision making on treatment value were viewed as heavily reliant on NCCN/ASCO guidelines (and related pathways) and available clinical trial results. Providers were most commonly influenced by P\&T committees' assessment of drug value through formulary restrictions including drug exclusion lists, preferred drug treatments based on manufacturer contracting, and internal clinical pathways.

While providers noted the infrequency of direct manufacturer contracting or placement of drugs on exclusion lists, 83\% of participants' organizations employed some form of internal clinical pathway. Despite the high prevalence of internal clinical pathway use, providers discussed the nonbinding nature of existing pathways. Providers with internal clinical pathways integrated in their electronic medical record (EMR) systems (25\%), as opposed to web- or computer-based applications, described greater influence of internal pathways due to the automatic provision of pathway-based recommendations in the treatment decision process. Although greater adoption of internal pathways was viewed as likely in the future, only a few practices were considering further pathway integration in their EMR systems.

Oncology Provider Evidence Needs Going Forward. Despite the ongoing shift from volume- to value-based care, many providers anticipated little change in their future evidence needs to help inform drug treatment value. Others identified a need for new evidence sources and timelier/holistic value-based information, as well as improved collaboration and communication between manufacturers and providers.

Although providers expected clinical trials and treatment guidelines (e.g., NCCN) to remain the most important evidence sources for drug value and formulary assessments for new therapies, some recognized that other information such as evidence regarding optimal drug treatment combinations, high clinical unmet need, real-world treatment efficacy, patient quality of life, and patient-reported outcomes could play a key role when clinical trial data or treatment guidelines were unavailable (Figure 4).

Participants also expressed a desire for more holistic and timely value-based information that could provide a summary of available data rather than a single cost estimate or conclusion. For these physicians, a holistic framework providing 


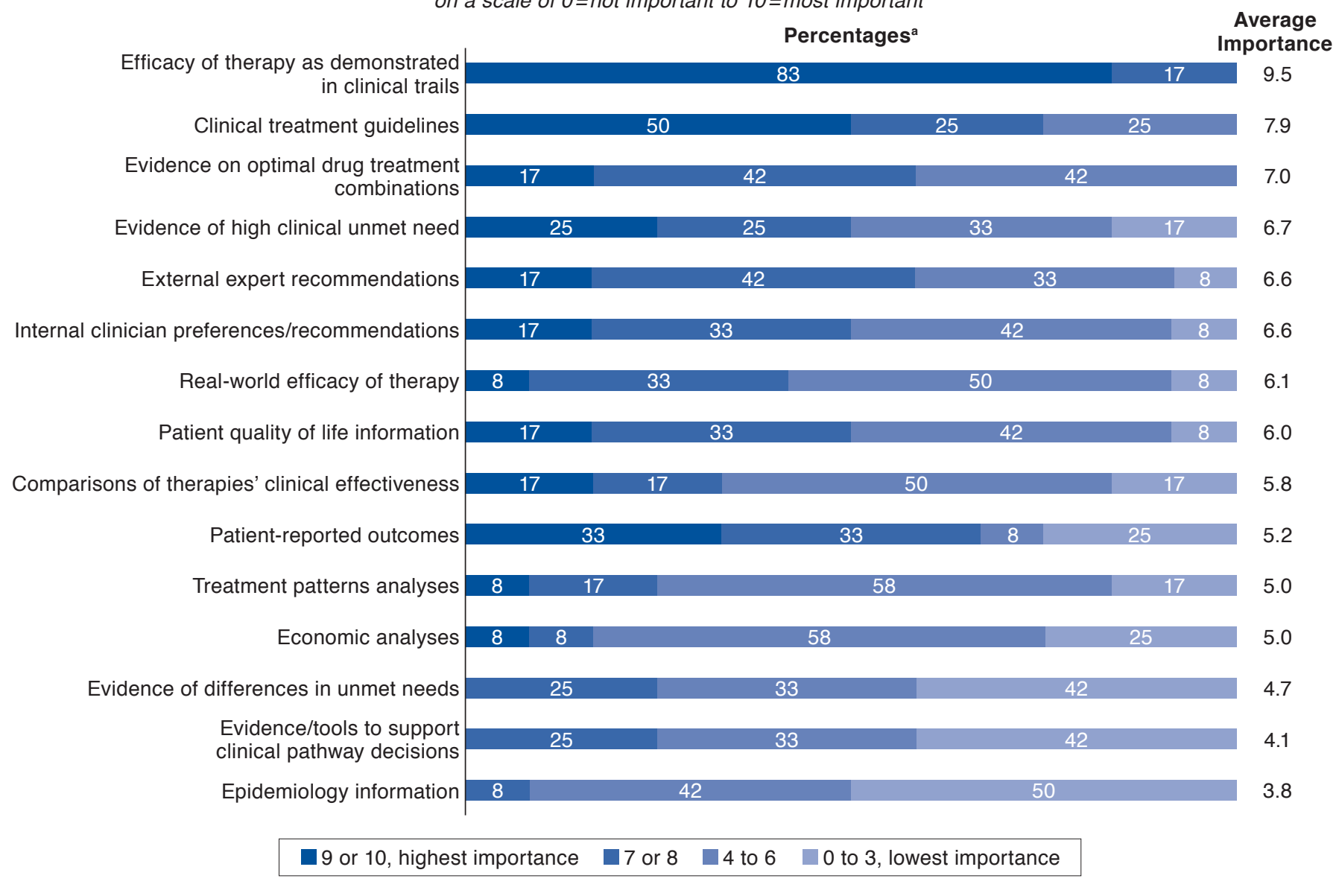

aPercentages do not always equal $100 \%$, due to rounding.

comprehensive and multifaceted information would be a useful tool for making the best complex treatment decisions for each patient (in contrast with current provider-/patient-focused value frameworks, such as those from ASCO and NCCN value frameworks, that provide broad-brush information using a limited set of available evidence but are not actionable/customizable for a specific patient's treatment needs). Providers also discussed the limitations of existing provider-/patient-focused value frameworks in providing timely guidance to physicians for new therapies; by typically releasing framework scores a few years after treatments become available, such value frameworks are currently viewed as "after-the-fact scores" rather than tools for proactively incorporating new therapies into patient-level treatment decisions. While interviewed providers had some limited familiarity with value frameworks intended for use by payers and/or policymakers (e.g., MSKCC, ICER, and ESMO value frameworks), participant feedback suggests that these value frameworks are generally not relied upon by providers when making treatment decisions due to their focus on population-level (rather than patient-level) outputs and characteristics.

In addition to interest in the development of timelier and multifaceted value frameworks, some providers mentioned the potential for further future collaboration between manufacturers and leading institutions in generating real-world evidence as the needs for understanding drug treatment value become more sophisticated. In general, providers viewed manufacturer data presentations as subject to bias and providing limited incremental information relative to publicly available evidence. For some providers, this was driven in part by the inability of manufacturer sales representatives to discuss information on 
therapies outside of their label (i.e., information not already available in the public domain).

\section{Discussion}

Consistent with previous literature, we found that large changes to the oncology landscape are occurring in response to payer efforts to restrain rising cancer drug costs. ${ }^{1,37,38}$ Historically insulated from such pressures, providers are increasingly being forced to consider value-based factors in their patient- and practice-level drug treatment decisions. ${ }^{10,16,26,39,40}$

\section{Value Assessment Is a Challenge for Providers}

Despite shared understanding among providers that payers expect a shift toward value-based drug treatment decisions, we find that assessing drug value remains a significant challenge for oncology providers. These challenges are largely driven by the need for providers to balance complex considerations when making their daily drug decisions, including (a) efficacy (including life and death considerations), (b) the focus on patient-level (not drug-level) decisions, and (c) limited visibility of economic considerations for payers/society beyond out-ofpocket payments for their patients.

Among the 12 providers interviewed, none had an explicit definition of value used by their organization to guide treatment/formulary decisions, and a clear, common framework does not exist to guide providers in drug value assessment. Moreover, both the literature review and provider interviews point to significant variability in value assessments across providers. ${ }^{26,27,34,37}$ Although clinical efficacy is commonly recognized as a critical consideration for most providers, substantial heterogeneity exists in how providers weigh implicit value decisions across other factors such as toxicity, quality of life, and affordability.

Although oncology providers are aware of value frameworks, ${ }^{21,41}$ few see value frameworks as influential to their treatment/formulary decisions or likely to become so without clearer guidance from payers and policymakers. Many of the providers who participated in our research indicated that their interest in value frameworks stemmed primarily from their perception of payer expectations; yet, in our experience, most payers currently do not see much relevance for value frameworks in guiding oncology decision making. As this disconnect illustrates, more guidance is needed from payers if they want providers to move toward greater value-based decision making.

The lack of literature references to the use of value frameworks in existing U.S. value-based arrangements for oncology therapies is consistent with the authors' experience and prior research among U.S. payers and manufacturers, which found no evidence of value-framework use in value-based arrangements for oncology therapies. ${ }^{42}$

\section{Provider Need for a Holistic Value Platform}

In recent years, much of the discussion surrounding value in oncology has focused on value frameworks and providing an approach for drug selection across patients..$^{37,43}$ In contrast, interviewed providers expressed a need for a value platform or tool that would provide for a given patient a comprehensive and timely summary of available data informing value, from a holistic/multifaceted perspective, rather than a single-point estimate/conclusion (e.g., as with the MSKCC and ICER value frameworks). The need for such a value platform was seen as particularly acute for new therapies as information is typically less readily available.

As an alliance of some of the leading U.S. cancer centers, in collaboration with payers and patient groups (e.g., America's Health Insurance Plans, Academy of Managed Care Pharmacy, and American Cancer Society), NCCN could be an important forum for providing such a value-based decision-making platform in oncology. Provider feedback suggests that the NCCN Evidence Blocks are the most well-known and appreciated value frameworks; however, both our research and existing literature suggest that the framework may benefit by becoming a more comprehensive and transparent tool, focusing on patient-specific treatment., ${ }^{4}$ The addition of new blocks to capture patient-centric value considerations, such as quality of life; treatment-regimen complexity; and economic elements, such as copayment affordability, may add to this flexibility. Furthermore, recent efforts to introduce such patient considerations, including the patient-perspective value framework, may also improve value-framework usability by offering increased flexibility and relevance as a shared treatment decision-making tool for patients and providers. ${ }^{44,45}$ Over time, physician education on value-based decision making will be critical and should be an important focus for medical schools and continuing medical education.

\section{Manufacturer-Provider Considerations}

Provider feedback in this research identifies significant challenges for oncology drug manufacturers to appropriately communicate the value of their therapies due to provider concerns regarding bias and sales representatives' inability to communicate information beyond a product's label. The ability to communicate off-label considerations is all the more significant for providers to be well informed about product-label information and emerging-treatment uses, the latter of which is often initially off-label. As such, information that can be provided by medical science liaisons may be more valuable in addressing providers' expressed evidence needs compared to information provided by sales representatives.

Thus, manufacturers in oncology should consider a more scientific approach toward partnering with providers. Such novel approaches could potentially include (a) deeper collaborations with leading/largest oncology care institutions to 
generate real-world evidence and inform treatment best practices and (b) greater emphasis on a communication model led by scientific-staff (e.g., medical science liaisons, health economics and outcomes research value $\&$ evidence liaisons, or medical directors). ${ }^{46,47}$ Food and Drug Modernization Act Section 114 and Section 3037 of the 21st Century Cures Act provide a potential avenue for such scientific exchanges to become more common in how manufacturers, providers, and payers communicate about value. ${ }^{48-50}$ Notably, Section 3037 and the associated U.S. Food and Drug Administration guidance on health care economic information communication in June 2018 significantly broadened the potential for manufacturers to share with payers any analysis that identifies, measures, or describes the economic consequences of the use of a drug (including clinical data, inputs, clinical assumptions, methods, results, and other components underlying or comprising the analysis). ${ }^{49,50}$ With greater consolidation of the oncology provider landscape, leading centers now often have enough patients to conduct meaningful real-world studies. Increased practice consolidation may also aid communication with manufacturers, allowing scientifically trained staff to share information regarding unmet needs, treatment value, and potential differences across patient populations.

\section{Limitations}

Some limitations to this work need to be considered. The literature review included studies based on specific keyword database searches of articles published between January 1974 and November 2017. Thus, the review may have excluded relevant studies not captured by these searches. Also, provider interview research findings from this study are based on data from qualitative interviews, which may be subjective and prone to participant selection and recall bias. Furthermore, although efforts were made to recruit participants from a broad range of oncology provider organizations, the study sample of 12 U.S. oncology providers may not be representative of the overall U.S. oncology provider landscape. Notably, the perspectives of some provider groups (e.g., solo practitioners) were not included in the current sample. Finally, the extent to which the perspectives of interviewed providers are representative of the views among other experts within their organizations was not assessed.

\section{Conclusions}

In a rapidly changing landscape, oncology providers require improved guidance from payers and policymakers to help define drug value in oncology. This study identifies a need for a more robust and multifaceted value platform in oncology: a tool that would provide a holistic and timely summary of information required to assess the value of treatment options for a given patient. NCCN, in collaboration with payer and patient groups, will likely have a critical role to play in supporting the development of such a platform. Manufacturers also need to make significant strides to help generate real-world evidence and better communicate the value of their therapies.

\section{Authors}

CHRISTIAN FROIS, PhD; JOHN JARVIS, MBA; and KATHRYN GRICE, BA, Analysis Group, Boston, Massachusetts. ANDREW HOWE, PharmD; KEN WONG, PharmD; CHRISTOPHER ZACKER, PhD; and RAHUL SASANE, PhD, Novartis Pharmaceuticals, East Hanover, New Jersey.

AUTHOR CORRESPONDENCE: Christian Frois, PhD, Vice President, Analysis Group, 111 Huntington Ave., 14 Fl., Boston, MA 02199. Tel.: 617.425.8304; E-mail: Christian.Frois@analysisgroup.com.

\section{DISCLOSURES}

Funding for this work was provided by Novartis Pharmaceuticals. The study sponsor was involved in study design, data interpretation, and data review. All authors contributed to the development of the manuscript and maintained control over the final content. Sasane, Howe, Wong, and Zacker were employees of Novartis at the time of this study. Frois, Jarvis, and Grice are or have been employed by Analysis Group, which received a grant from Novartis for this research. At the time of this study, Analysis Group received funding from multiple manufacturers with oncology products in their portfolio during this time period, including, but not limited to, Astellas and Genentech.

\section{REFERENCES}

1. Tangka FK, Trogdon JG, Richardson LC, et al. Cancer treatment cost in the United States: has the burden shifted over time? Cancer. 2010;116(14):3477-84.

2. Fitch K, Pelizzari P, Pyenson B; Community Oncology Alliance. Cost drivers of cancer care: a retrospective analysis of Medicare and commercially insured population claim data 2004-2014. April 2016. Available at: http:// www.milliman.com/uploadedFiles/insight/2016/trends-in-cancer-care.pdf. Accessed November 30, 2018.

3. Agency for Healthcare Research and Quality. Medical expenditure panel survey: total expenses and percent distribution for selected conditions by type of service: United States, 2014. 2014. Available at: https://meps ahrq.gov/mepsweb/data_stats/tables_compendia_hh_interactive.jsp? SERVICE=MEPSSocket0\&_PROGRAM=MEPSPGM.TC.SAS\&File=HCFY201 $4 \&$ Table=HCFY2014_CNDXP_C\&_Debug=. Accessed November 30, 2018.

4. Sorenson C, Lavezzari G, Daniel G, et al. Advancing value assessment in the United States: a multistakeholder perspective. Value Health. 2017;20(2):299-307.

5. Miller AM, Omenn GS, Kean MA. The impact of alternative payment models on oncology innovation and patient care. Clin Cancer Res. 2016;22(10):2335-41

6. Reh G, Morris M, Shah S, Naaz B; Deloitte Center for Health Solutions. The evolution of oncology payment models: what can we learn from early experiments? 2016. Available at: https://www2.deloitte.com/content/dam/ Deloitte/us/Documents/life-sciences-health-care/us-lshc-evolution-of-oncology-payment-models.pdf. Accessed November 30, 2018.

7. Shah S, Reh G; Deloitte Center for Health Solutions. Value-based payment models in oncology: will they help or hinder patient access to new treatments? Am J Manag Care. 2017;23(5 Spec No.):SP188-SP190. Available at: http://www.ajmc.com/journals/evidence-based-oncology/2017/april-2017/ value-based-payment-models-in-oncology-will-they-help-or-hinder-patientaccess-to-new-treatments. Accessed November 30, 2018.

8. Cox JV, Ward JC, Hornberger JC, Temel JS, McAneny BL. Community oncology in an era of payment reform. Am Soc Clin Oncol Educ Book. 2014:e447-52. 
9. Genentech. The 2017 Genentech oncology trend report: perspectives from managed care organizations, specialty pharmacies, oncologists, practice managers, and employers. 9th ed. South San Francisco, CA: Genentech; 2017.

10. Polite B, Conti RM, Ward JC. Reform of the buy-and-bill system for outpatient chemotherapy care is inevitable: perspectives from an economist, a realpolitik, and an oncologist. Am Soc Clin Oncol Educ Book. 2015:e75-80.

11. Werble C. Medicare Part B. Health Affairs. Health policy brief \#5. August 10, 2017. Available at: https://www.healthaffairs.org/do/10.1377/ hpb20171008.000171/full/. Accessed December 2, 2018.

12. Dummit LA. Medicare chemotherapy payments: new drug and administration fees are closer to providers' costs [letter]. Government Accountability Office. GAO-05-142R. December 1, 2004. Available at: https://www.gao.gov/ assets/100/92938.pdf. Accessed December 2, 2018.

13. Polite BN, Ward JC, Cox JV, et al. Payment for oncolytics in the United States: a history of buy and bill and proposals for reform. J Oncol Pract. 2014;10(6):357-62.

14. Weber S. Five trends emerge in payer management of oncology. Am J Manag Care. 2013;19(Spec No 3):E3. Available at: https://www.ajmc.com/ journals/evidence-based-oncology/2013/2013-1-vol19-sp3/five-trendsemerge-in-payer-management-of-oncology. Accessed December 3, 2018.

15. US Oncology. US Oncology Pulse Survey results: oncologists report declining reimbursement: most significant challenge for future practice viability. 2009. Available at: https://www.accc-cancer.org/docs/docs-imported/ mediaroom/pdf/media-usoncology2009survey. Accessed December 2, 2018.

16. Community Oncology Alliance. 2016 community oncology practice impact report: tracking the changing landscape of cancer care. October 4, 2016. Available at: http://www.communityoncology.org/wp-content/ uploads/2016/09/PracticeImpactReport-2016-Report.pdf. Accessed December 2, 2018.

17. Avalere Health. Clinical pathways: overview of current practices and potential implications for patients, payers, and providers. July 2015.

Available at: https://www.phrma.org/report/clinical-pathways-overview-ofcurrent-practices-and-potential-implications-for-patients-payers-and-providers. Accessed January 11, 2019.

18. Schnipper LE, Davidson NE, Wollins DS, et al. Updating the American Society of Clinical Oncology value framework: revisions and reflections in response to comments received. J Clin Oncol. 2016;34(24):2925-34.

19. National Comprehensive Cancer Network. NCCN clinical practice guidelines (NCCN Guidelines) in oncology with NCCN Evidence Blocks. 2016. Available at: https://www.nccn.org/evidenceblocks/. Accessed December 2, 2018.

20. Memorial Sloan Kettering Cancer Center. DrugAbacus. 2018. Available at: https://drugpricinglab.org/tools/drug-abacus/. Accessed December 2, 2018.

21. Slomiany M, Madhavan P, Kuehn M, Richardson S. Value frameworks in oncology: comparative analysis and implications to the pharmaceutical industry. Am Health Drug Benefits. 2017;10(5):253-60.

22. Green M, DiPaula K. The path toward drug value definition: implications of value initiatives in oncology. White paper. March 2016. Kantar Health. New York, NY.

23. Avalere Health. Dimensions: specialty management solutions. Issue brief: clinical pathways. 2016. Avalere Health. Washington, DC.

24. Moher D, Liberati A, Tetzlaff J, Altman D; PRISMA Group. Preferred reporting items for systematic reviews and meta-analyses: the PRISMA statement. Ann Intern Med. 2009;151(4):264-69.

25. Cohen JT, Anderson JE, Neumann PJ. Three sets of case studies suggest logic and consistency challenges with value frameworks. Value Health 2017;20(2):193-99.

26. Narayanan S, Hautamaki E. Oncologist support for consolidated payments for cancer care management in the United States. Am Health Drug Benefits. 2016;9(5):280-89.
27. Waldeck AR, Botteman MF, White RE, van Hout BA. The importance of economic perspective and quantitative approaches in oncology value framework of drug selection and shared decision making. J Manag Care Spec Pharm. 2017;23(6-a suppl):S6-12. Available at: https://www.jmcp.org/ doi/10.18553/jmcp.2017.23.6-a.s6.

28. Neumann P, Palmer J, Nadler E, Fang C, Ubel P. Cancer therapy costs influence treatment: a national survey of oncologists. Health Aff (Millwood). 2010;29(1):196-202.

29. Schnipper L, Davidson N, Wollins D, et al. American Society of Clinical Oncology Statement: a conceptual framework to assess the value of cancer treatment options. J Clin Oncol. 2015;33(23):2563-77.

30. Institute for Clinical and Economic Review. Overview of the ICER value framework and proposals for an update for 2017-2018. February 1, 2017. Available at: http://icer-review.org/wp-content/uploads/2016/02/ICER-VAFUpdate-Proposals-020117.pdf. Accessed December 2, 2018.

31. European Society for Medical Oncology. ESMO Magnitude of Clinical Benefit Scale. 2017. Available at: https://www.esmo.org/score/cards. Accessed December 2, 2018.

32. Shah-Manek B, Galanto J, Nguyen H, Ignoffo R. Value frameworks for the patient-provider interaction: a comparison of the ASCO value framework versus NCCN Evidence Blocks in determining value in oncology. J Manag Care Spec Pharm. 2017;23(6-a suppl):S13-20. Available at: https://www.jmcp. org/doi/10.18553/jmcp.2017.23.6-a.s13.

33. Cheng S, McDonald EJ, Cheung MC, et al. Do the American Society of Clinical Oncology Value Framework and the European Society of Medical Oncology Magnitude of Clinical Benefit Scale measure the same construct of clinical benefit? J Clin Oncol. 2017;35(24):2764-71.

34. Wilson L, Lin T, Wang L, et al. Evaluation of the ASCO value framework for anticancer drugs at an academic medical center. J Manag Care Spec Pharm. 2017;23(2):163-69. Available at: https://www.jmcp.org/doi/10.18553/ jmcp.2017.23.2.163.

35. Li J, Asabere A, Cho Y, et al. Application of ASCO value framework evaluations of net health benefit for oncology drugs launched in the United States between 2013 and 2015. Value Health. 2015;18(7):A489.

36. Maervoet J, Moise P, Naidoo S. Overview and comparison of frameworks for the valuation of oncology drugs. Value Health. 2016;19(3):A168.

37. Nabhan C, Feinberg BA. Value-based calculators in cancer: current state and challenges. J Oncol Pract. 2017;13(8):499-506.

38. Rocque GB, Williams CP, Kenzik KM, et al. Where are the opportunities for reducing health care spending within alternative payment models? J Oncol Pract. 2018;14(6):e375-83.

39. Vandervelde A. 340B growth and the impact on the oncology marketplace. Berkeley Research Group. White paper. September 2015. Available at: https://www.communityoncology.org/pdfs/BRG_COA_340B-Report_9-15. pdf. Accessed January 10, 2019.

40. Feinberg B, Feinberg I. Overall survival of the medical oncologist: a new outcome measurement in cancer measurement. Cancer. 1998;82(S10):2047-56. 41. Lederman L. Value tools at ASCO 2016: building a framework for prime time. 2018. Available at: www.zs.com/publications/articles/value-tools-at-asco2016-building-a-framework-for-prime-time.aspx. Accessed December 2, 2018.

42. Nazareth T, Ko J, Sasane R, et al. Outcomes-based contracting experience: research findings from U.S. and European stakeholders. J Manag Care Spec Pharm. 2017;23(10):1018-2026. Available at: https://www.jmcp.org/ doi/10.18553/jmcp.2017.23.10.1018.

43. Goulart BHL. Value: the next frontier in cancer care. Oncologist. 2016;21(6):651-53.

44. Avalere Health. Patient-perspective value framework. Version 1.0. May 2017. Available at: http://www.fastercures.org/assets/Uploads/PPVF-Version1.0-Methodology-Report-Final.pdf. Accessed December 2, 2018. 
45. Doshi J, Sonet E, Puckett J Glick E. The need for a new patient-centered decision tool for value-based treatment choices in oncology. Health Affairs Blog. March 21, 2018. Available at: https://www.healthaffairs.org/ do/10.1377/hblog20180309.241877/full/. Accessed December 2, 2018.

46. Jarvis S, John S, Gonzales J, Gopalan S. ZS Medical Affairs outlook report 2017: analysis of field medical growth and industry trends. ZS Medical Affairs. 2017. Available at: https://www.zs.com/-/media/pdfs/zsmedicalaffairsoutlookreport2017web.pdf?la=en. Accessed December 2, 2018.

47. Myshko D. The evolution of the MSL. PharmaVOICE. September 2017. Available at: http://www.pharmavoice.com/article/2017-9-msl/. Accessed December 2, 2018 .
48. Perfetto E, Burke L, Oehrlein EM Gaballah M. FDAMA Section 114: why the renewed interest? J Manag Care Spec Pharm. 2015;21(5):368-74. Available at: https://www.jmcp.org/doi/10.18553/jmcp.2015.21.5.368.

49. U.S. Food and Drug Administration. Drug and device manufacturer communications with payors, formulary committees, and similar entities: questions and answers. Guidance for industry and review staff. 2018. Available at: https://www.fda.gov/downloads/drugs/guidancecomplianceregulatoryinformation/guidances/ucm537347.pdf. Accessed December 2, 2018.

50. Neumann PJ, Pope E. Cures Act, FDA draft guidance suggest flexibility on communication of real-world drug impacts, though questions remain. Health Affairs Blog. February 2, 2017. Available at: https://www.healthaffairs.org/ do/10.1377/hblog20170202.058584/full/. Accessed December 2, 2018. 


\section{APPENDIX A Literature Review}

Methods

The literature review was conducted during November 2017 (see figure below). The search strategy employed to identify eligible articles involved the following keyword searches of the MEDLINE, Embase, and PubMed databases:

- "Value in oncology" or "value in cancer"

- Value framework-related

"ASCO" AND "value framework"

"NCCN" AND "evidence blocks"

("MSKCC" or "Sloan Kettering") AND "Abacus"

"Institute for Clinical and Economic Review" AND ("cancer" OR "oncology")

- Alternative payment models related:

"alternative payment models" AND ("oncology care" OR "cancer care")

" "value" AND "model" AND ("oncology care" OR "cancer care")

"patient-centered medical home" AND ("oncology care" OR "cancer care")

"bundled payment" AND ("oncology care" OR "cancer care")

Only full-text articles in the English language were considered with no restrictions to date range. Two independent reviewers screened titles and abstracts. Articles were excluded based on the following criteria

- Article is a duplicate

- Article not focused on value-based care (e.g., clinical trial results)

- Article not policy focused (e.g., cost-effectiveness analysis)

- Article not specific to oncology drug treatment

- Article is therapy-specific (e.g., single-drug focus)

- Article is a case report

- Article is a guideline (e.g., NCCN guidelines)

The eligible 29 articles were reviewed with a focus on the following information:

- Definition of drug value in oncology

- Characteristics and reported advantages/limitations of new oncology value frameworks (e.g., ASCO, MSKCC, NCCN, ICER, DrugAbacus)

- Impact of value frameworks on future oncology care and payment models

\section{PRISMA Diagram for Study Selection}

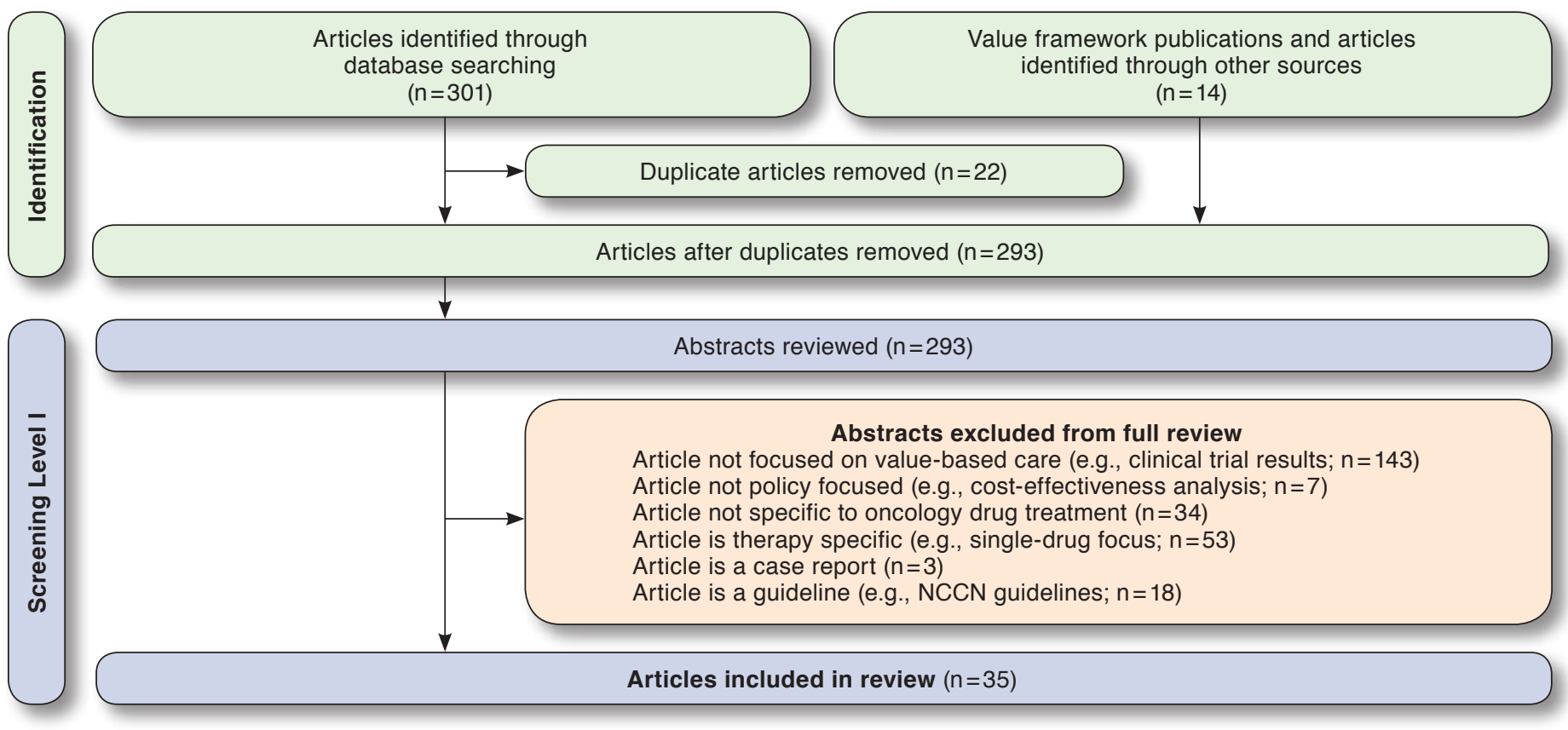




\section{Full List of Articles Reviewed}

Cheng S, McDonald EJ, Cheung MC, et al. Do the American Society of Clinical Oncology Value Framework and the European Society of Medical Oncology Magnitude of Clinical Benefit Scale measure the same construct of clinical benefit? J Clin Oncol. 2017;35(24):2764-71.

Cohen JT, Anderson JE, Neumann PJ. Three sets of case studies suggest logic and consistency challenges with value frameworks. Value Health. 2017:20:193-99.

Cox JV, Ward JC, Hornberger JC, Temel JS, McAneny BL. Community oncology in an era of payment reform. Am Soc Clin Oncol Educ Book. 2014:e447-52

Ersek JL, Nadler E, Freeman-Daily J, Mazharuddin S, Kim ES. Clinical pathways and the patient perspective in the pursuit of value-based oncology care. Am Soc Clin Oncol Educ Book. 2017;37:597-606.

European Society for Medical Oncology. ESMO Magnitude of Clinical Benefit Scale. 2017. Available at: https://www.esmo.org/score/cards. Accessed December 2, 2018.

Falit BP, Chernew ME, Mantz CA. Design and implementation of bundled payment systems for cancer care and radiation therapy. Int $J$ Radiat Oncol Biol Phys. 2014:89(5):950-53.

Feeley TW, Fy HS, Albright H, Walters R, Burke TW. A method for defining value in healthcare using cancer care as a model. J Healthc Manag. 2010;55(6):399-412.

Institute for Clinical and Economic Review. Overview of the ICER value framework and proposals for an update for 2017-2018. February 1, 2017. Available at: http://icer-review.org/wp-content/uploads/2016/02/ICER-VAFUpdate-Proposals-020117.pdf. Accessed December 2, 2018.

Kline RM, Bazell C, Smith E, et al. Centers for Medicare and Medicaid Services: using an episode-based payment model to improve oncology care. J Oncol Pract. 2015;11(2):114-16.

Li J, Asabere A, Kelly S, Cho Y, Dua D, Bastian A. Application of the ASCO value framework evaluations of net health benefit for oncology drugs launched in the United States between 2013 and 2015. Value Health. 2015;18(7):A489.

Lin WJ; University of North Carolina Chapel Hill. Comparison of U.S. oncology value frameworks and integration with performance-based pricing. 2017. Available at: https://cdr.lib.unc.edu/indexablecontent/ uuid:c83b2e55-89ae-48fc-bd95-0f8a90bfc0be. Accessed December 2, 2018

Maervoet J, Moise P, Naidoo S. Overview and comparison of frameworks for the valuation of oncology drugs. Value Health. 2016;19(3):Al68.

Mandelblatt JS, Ramsey SD, Lieu TA, Phelps CE. Evaluating frameworks that provide value measures for health care interventions. Value Health. 2017;20:185-92

Memorial Sloan Kettering Cancer Center. DrugAbacus. 2018. Available at: https://drugpricinglab.org/tools/drug-abacus/. Accessed December 2, 2018

Miller AM, Omenn GS, Kean MA. The impact of alternative payment models on oncology innovation and patient care. Clin Cancer Res. 2016;22(10):2335-41

Nabhan C, Feinberg BA. Value-based calculators in cancer care: current states and challenges. J Oncol Pract. 2017;13(8):499-506.

Narayanan S, Hautamaki E. Oncologist support for consolidated payments for cancer care management in the United States. Am Health Drug Benefits. 2016;9(5):280-89.

National Comprehensive Cancer Network. NCCN clinical practice guidelines (NCCN Guidelines) in oncology with NCCN Evidence Blocks. 2016. Available at: https://www.nccn.org/evidenceblocks/. Accessed December 2, 2018.
Neubauer M. The U.S. Oncology Network boot camp provides expertise, gathers feedback about value-based care. 2017. Available at: https:// www.healio.com/hematology-oncology/practice-management/news/ online/\%7B94f5ed0b-ef25-4025-ab90-3e9bb9416f80\%7D/the-us-oncologynetwork-boot-camp-provides-expertise-gathers-feedback-about-value-basedcare. Accessed December 2, 2018.

Paddock S, Brum L, Sorrow K, et al. PACE Continuous Innovation Indicators: a novel tool to measure progress in cancer treatments. Ecancermedicalscience. 2015;9;498.

Page RD, Newcomer LN, Sprandio JD, McAneny BL. The patient-centered medical home in oncology: from concept to reality. Am Soc Clin Oncol Educ Book. 2015:e82-89.

Polite B, Walradt J. Pursuing value in cancer care: a model in progress. J Pract Oncol. 2017;13(7):407-09.

Precision Health Economics. Innovations in cancer care: capturing what patients value in the calculus of drug costs [research brief]. 2017. Available at: https://www.precisionmedicinegrp.com/pfv/wp-content/uploads/ sites/2/2017/03/PHE-Cancer-Brief.pdf. Accessed December 2, 2018.

Rocque GB, Williams CP, Kenzik KM, et al. Where are the opportunities for reducing health care spending within alternative payment models? J Oncol Pract. 2018;14(6):e375-83.

Sanghavi D, Samuels K, George M, et al. Case study: transforming cancer care at a community oncology practice. Healthc (Amsterdam). 2015;3:160-68.

Schnipper L, Davidson N, Wollins D, et al. American Society of Clinical Oncology Statement: a conceptual framework to assess the value of cancer treatment options. J Clin Oncol. 2015;33(23):2563-77.

Schnipper LE, Davidson NE, Wollins DS, et al. Updating the American Society of Clinical Oncology value framework: revisions and reflections in response to comments received. J Clin Oncol. 2016;34(24):2925-34.

Shah S, Reh G; Deloitte Center for Health Solutions. The evolution of oncology payment models: what can we learn from early experiments? 2016. Available at: https://www2.deloitte.com/content/dam/Deloitte/us/ Documents/life-sciences-health-care/us-lshc-evolution-of-oncology-payment-models.pdf. Accessed December 2, 2018.

Shah-Manek B, Galanto JS, Nguyen H, Ignoffo R. Value frameworks for the patient-provider interaction: a comparison of the ASCO value framework versus NCCN Evidence Blocks in determining value in oncology. J Manag Care Spec Pharm. 2017;23(6-a suppl):S13-20. Available at: https://www.jmcp. org/doi/10.18553/jmcp.2017.23.6-a.s13.

Slomiany M, Madhavan P, Kuehn M, Richardson S. Value frameworks in oncology: comparative analysis and implications to the pharmaceutical industry. Am Health Drug Benefits. 2017;10(5):253-60.

Sorenson C, Lavezzari G, Daniel G, et al. Advancing value assessment in the United States: a multistakeholder perspective. Value Health. 2017;20:299-307.

Waldeck AR, Botteman MF, White RE, van Hout BA. The importance of economic perspective and quantitative approaches in oncology value frameworks of drug selection and shared decision making. J Manag Care Spec Pharm. 2017;23(6-a suppl):S6-12. Available at: https://www.jmcp.org/ doi/10.18553/jmcp.2017.23.6-a.s6

Westrich K; National Pharmaceutical Council. Current landscape: value assessment frameworks. March 16, 2016. Available at: https://www.npcnow. org/publication/current-landscape-value-assessment-frameworks. Accessed December 2, 2018.

Wilson L, Lin T, Wang L, et al. Evaluation of the ASCO value framework for anticancer drugs at an academic medical center. J Manag Care Spec Pharm. 2017;23(2):163-69. Available at: https://www.jmcp.org/doi/10.18553/ jmcp.2017.23.2.163.

Yu PP. Challenges in measuring cost and value in oncology: making it personal. Value Health. 2016;19(5):520-24. 


\begin{tabular}{|c|c|c|c|c|c|}
\hline & $\begin{array}{l}\text { ASCO Value } \\
\text { Framework }\end{array}$ & $\begin{array}{c}\text { NCCN } \\
\text { Evidence Blocks }\end{array}$ & $\begin{array}{l}\text { ESMO Magnitude of } \\
\text { Clinical Benefit Scale }\end{array}$ & $\begin{array}{l}\text { ICER Value } \\
\text { Framework }\end{array}$ & $\begin{array}{c}\text { MSKCC } \\
\text { DrugAbacus }\end{array}$ \\
\hline \multicolumn{6}{|l|}{ Value considerations ${ }^{1,3}$} \\
\hline Treatment efficacy & $\checkmark$ & $\checkmark$ & $\checkmark$ & $\checkmark$ & $\checkmark$ \\
\hline Toxicity & $\checkmark$ & $\checkmark$ & $\checkmark$ & $\checkmark$ & $\checkmark$ \\
\hline Quality of life/palliation & $\checkmark$ & & $\checkmark$ & $\checkmark$ & \\
\hline Treatment-free interval & $\checkmark$ & & & & \\
\hline $\begin{array}{l}\text { Quality/consistency of } \\
\text { evidence }\end{array}$ & & $\checkmark$ & & & $\checkmark$ \\
\hline $\begin{array}{l}\text { Disease burden/incidence } \\
\text { and unmet need }\end{array}$ & & & & $\checkmark$ & $\checkmark$ \\
\hline Novelty of therapy & & & & & $\checkmark$ \\
\hline Drug cost & $\checkmark$ & $\checkmark$ & & $\checkmark$ & $\checkmark$ \\
\hline \multicolumn{6}{|l|}{ Features ${ }^{3}$} \\
\hline Survival measure & OS, PFS & OS & OS, PFS & $\begin{array}{l}\text { Varies depending } \\
\text { on indication }\end{array}$ & OS \\
\hline Other efficacy measures & $\begin{array}{l}\text { Response rate, } \\
\text { hazard ratio }\end{array}$ & Expert opinion & $\begin{array}{l}\text { Response rate, } \\
\text { palliation }\end{array}$ & $\begin{array}{l}\text { Varies depending } \\
\text { on indication }\end{array}$ & \\
\hline Safety/toxicity & $\begin{array}{c}\text { Side effect } \\
\text { frequency, grade }\end{array}$ & Effect on daily life & $\begin{array}{c}\text { Grade } 3 / 4 \text {, severe } \\
\text { side effects }\end{array}$ & Severe side effects & $\begin{array}{c}\text { Grade } 3 / 4 \text {, probability of } \\
\text { discontinuing }\end{array}$ \\
\hline Drug cost & $\begin{array}{c}\text { Drug acquisition } \\
\text { cost }\end{array}$ & $\begin{array}{l}\text { Total treatment cost, } \\
\text { affordability }\end{array}$ & Not specified & $\begin{array}{c}\text { Total cost/person, total } \\
\text { cost to payers }\end{array}$ & ASP/AWP \\
\hline Evidence considered & Single RCT & $\begin{array}{l}\text { Published data, } \\
\text { expert opinion, } \\
\text { case reports }\end{array}$ & $\begin{array}{c}\text { Single RCT, } \\
\text { comparative outcomes } \\
\text { study, meta-analyses }\end{array}$ & $\begin{array}{l}\text { RCT meta-analysis, } \\
\text { manufacturer- } \\
\text { provided data }\end{array}$ & Single RCT \\
\hline $\begin{array}{l}\text { Evidence sample size } \\
\text { considered? }\end{array}$ & No & Yes & Indirectly & Yes & Yes \\
\hline \multicolumn{6}{|l|}{ Framework intent 3,4} \\
\hline Intended audience & Physician, patient & Physician, patient & Payer, policymaker & Payer, policymaker & Payer, policymaker \\
\hline Description of output & $\begin{array}{c}\text { Qualitative value } \\
\text { assessment }\end{array}$ & $\begin{array}{c}\text { Qualitative value } \\
\text { assessment }\end{array}$ & $\begin{array}{c}\text { Qualitative value } \\
\text { assessment }\end{array}$ & $\begin{array}{c}\text { Value-based price } \\
\text { benchmark }\end{array}$ & $\begin{array}{c}\text { Value-based price } \\
\text { benchmark }\end{array}$ \\
\hline \multicolumn{6}{|l|}{ Advantages/limitations 1-4 $^{-4}$} \\
\hline Advantages & $\begin{array}{l}\text { - Bonus points add } \\
\text { flexibility and consid- } \\
\text { eration of QoL } \\
\text { - Applications to adju- } \\
\text { vant and metastatic } \\
\text { disease settings } \\
\text { - May be utilized as } \\
\text { a tool for shared } \\
\text { patient-provider } \\
\text { decision making }\end{array}$ & $\begin{array}{l}\text { - Graphical represen- } \\
\text { tation offers clarity } \\
\text { and ability to quickly } \\
\text { compare treatment } \\
\text { options } \\
\text { - Framework blocks are } \\
\text { modular and allow for } \\
\text { easy expansion } \\
\text { - May be utilized as } \\
\text { a tool for shared } \\
\text { patient-provider } \\
\text { decision making }\end{array}$ & $\begin{array}{l}\text { - Evaluates curative } \\
\text { and noncurative } \\
\text { drugs on different } \\
\text { scales }\end{array}$ & $\begin{array}{l}\text { - Considers stakeholder } \\
\text { input } \\
\text { - Detailed guidance for } \\
\text { using/interpreting } \\
\text { findings } \\
\text { - Employs multiple } \\
\text { sources of evidence }\end{array}$ & $\begin{array}{l}\text { - Adjustment factors } \\
\text { allow patient-input on } \\
\text { preference/value } \\
\text { - Considers other mea- } \\
\text { sures of value (e.g., } \\
\text { innovativeness, rarity } \\
\text { of disease) }\end{array}$ \\
\hline Limitations & $\begin{array}{l}\text { - Limited consideration } \\
\text { of evidence } \\
\text { (single RCT) } \\
\text { - Does not provide } \\
\text { cost/price estimate }\end{array}$ & $\begin{array}{l}\text { - Panel assessment and } \\
\text { model formulation } \\
\text { lack clarity } \\
\text { - Scores reflect } \\
\text { expected results of } \\
\text { "average" patient } \\
\end{array}$ & $\begin{array}{l}\text { - No consideration of } \\
\text { cost } \\
\text { - Rankings are based } \\
\text { on expert assessment }\end{array}$ & $\begin{array}{l}\text { - 5-year time horizon } \\
\text { may undervalue long- } \\
\text { term benefits } \\
\text { - Benefits/toxicities } \\
\text { based on expert } \\
\text { assessment } \\
\end{array}$ & $\begin{array}{l}\text { - Value not } \\
\text { explicitly defined }\end{array}$ \\
\hline
\end{tabular}

$\checkmark=$ Included in calculation/algorithm; $\checkmark=$ Shown for information/comparison purposes only.

ASCO = American Society of Clinical Oncology; ASP = average sales price; AWP = average wholesale price; ESMO=European Society for Medical Oncology;

ICER = Institute for Clinical and Economic Review; MSKCC= Memorial Sloan Kettering Cancer Center; NCCN= National Comprehensive Cancer Network; OS =overall survival; $P F S=$ progression-free survival; $Q$ QL = quality of life; $R C T=$ randomized controlled trial.

\section{REFERENCES}

1. Maervoet J, Moise P, Naidoo S. Overview and comparison of frameworks for the valuation of oncology drugs. Value Health. 2016;19(3):A168.

2. Nabhan C, Feinberg BA. Value-based calculators in cancer: current state and challenges. J Oncol Pract. 2017;13(8):499-506.
3. Slomiany M, Madhavan P, Kuehn M, Richardson S. Value frameworks in oncology: comparative analysis and implications to the pharmaceutical industry. Am Health Drug Benefits. 2017;10(5):253-60

4. Sorenson C, Lavezzari G, Daniel G, et al. Advancing value assessment in the United States: a multistakeholder perspective. Value Health. 2017;20(2):299-307. 